\section{Metastatic hypernephroma from a native kidney after cadaver renal transplantation}

Sir, Cystic degeneration of kidneys in patients with endstage renal failure and undergoing haemodialysis is well recognized. The incidence and extent of the cystic changes is related to the duration of the haemodialysis (Dunnil et al., 1977). Forty five percent of patients with these changes can expect to develop a hypernephroma, but there is only one recorded case of these tumours metastasizing. (Ratcliffe et al., 1983). A search through the literature and communication in the Transplant Tumour Registry has failed to reveal any previous reports of metastases from tumours in the native kidneys in patients who have undergone successful cadaver renal transplantation.

A 67 year old male developed end-stage renal failure due to a combination of diabetes mellitus, gout and hypertension. He commenced haemodialysis in January 1980 , and received a cadaver renal transplant six months later. He remained well for three and a half years, when he presented with recurrent urinary infections.

Examination revealed an obese man with signs of peripheral vascular disease. There was a hard, fixed lymph node in the right supraclavicular fossa. Biochemical investigations showed good graft function. Serum creatinine was $95 \mathrm{nmol} / \mathrm{l}$. Chest radiograph showed multiple lesions throughout both lung fields. Abdominal CT scan showed a mass at the inferior pole of his right native kidney. No abnormality was seen in the transplant kidney. A diagnosis of metastatic hypernephroma was made.

\section{S.C. Griffin \\ G. Williams \\ Department of Urology, Hammersmith Hospital, \\ London W12.}

\section{Acknowledgement}

We are grateful to Professor Allison, Department of Radiology, Hammersmith Hospital, for the radiological investigations.

\section{References}

DUNNIL, M.S., MILlARD, P.R. \& OLIVER, D.O. (1977). Acquired cystic disease of kidneys, the hazard of long-term intermittent haemodialysis. Journal of Clinical Pathology, 30, 868.

RATCLIFFE, P.J., DUNNIL, M.S. \& OLIVER, D.O. (1983). Clinical importance of acquired cystic disease of the kidney in patients undergoing dialysis. British Medical Journal, 287, 1855.

\section{Gallstone perforation of the ileum without obstruction}

Sir,

The case report (Shankar et al., 1984) of gallstone perforation of the ileum without obstruction was described as a sequel to asymptomatic gallstone impaction. Although the distal migration of a gallstone within the small bowel lumen is often asymptomatic, gallstone impaction must result in obstruction. The commonest site for this to occur is in the terminal ileum and it is the delay in presentation of such a distal small bowel obstruction which gives rise to the poor clinical condition of patients and high operative mortality (Van Landingham \& Broders, 1983). At laparotomy, it is not uncommon to find pressure necrosis at the site of impaction and with increasing tension within the ileal wall it is not surprising that perforation may occur either spontaneously or with surgical manipulation. Indeed, studies have shown that with an increase in faecal organisms due to obstruction, mucosal necrosis occurs early (Ellis, 1982). Perforation will allow the bowel to decompress with loss of the radiographic features of obstruction and the clinical picture changes to that of peritonitis. Clinical deterioration is rapid due to release of large volumes of small bowel content with a high concentration of faecal organisms consequent upon the obstruction (Ellis, 1982). This sudden severe peritonitis with septicaemia may be the initial clinical presentation of 'gall-stone ileus'. Recent experience of such a case is presented.

A 74 year old woman presented with a $6 \mathrm{~d}$ history of lower abdominal pain of sudden onset. Vomiting had been an early feature without abdominal distension. There was no past history of biliary tract disease. On examination she was dehydrated and toxic with signs of generalized peritonitis and a blood pressure of $70 /$ $50 \mathrm{~mm} \mathrm{Hg}$. Abdominal X-rays showed signs of a generalized ileus with gas and fluid in non-dilated small bowel and gas was present throughout the colon. After resuscitation, laparotomy was undertaken. A longstanding peritonitis was evident and a perforation was identified in the terminal ileum adjacent to a large gallstone. A cholecystoduodenal fistula was present containing a palpable gallstone and two further gallstones were present within the gallbladder. The gallstone was removed from the terminal ileum and the perforation closed transversely with sutures. The presence of further gallstones dictated cholecystectomy with excision of the fistulous tract and closure of the duodenum. Despite aggressive resuscitative measures including tetracycline, peritoneal lavage and systemic broad spectrum antibiotics (cefuroxime and 
metronidazole) per and post-operatively the patient remained in septic shock and died $12 \mathrm{~h}$ later.

D.S. Scrimgeour

A.D. Irving

Stracathro Hospital,

Brechin,

Angus DD9 7QA

\section{References}

ELLIS, H. (1982). Intestinal Obstruction, Appleton-CentsuryCrofts: New York.

SHANKAR, S., BRADLEY, J.W.P. \& PARKER, M. (1984). Gallstone perforation of the ileum without obstruction. Postgraduate Medical Journal, 60, 696.

VAN LANDINGHAM, S.B. \& BRODERS, C.W. (1982). Gallstone ileus. Surgical Clinics of North America, 62, 241.

\section{Failure of acetazolamide to prevent acute mountain sickness}

\section{Sir,}

I was the medical officer accompanying a recent trekking expedition to Nepal. As we were to ascend to $17,650 \mathrm{ft}$ over the Thorong $\mathrm{La}$, we acclimatized thoroughly, and all 14 members of the party took acetazolamide $250 \mathrm{mg}$ b.d., commenced $3 \mathrm{~d}$ before climbing above $10,000 \mathrm{ft}$.

At around 9,500-10,000 ft, a very fit 19 year old female member of our party became unwell and sought medical attention. She had felt nauseated and dizzy getting up that morning $(8,500 \mathrm{ft})$, but this feeling had partly disappeared and she managed to walk to $800 \mathrm{ft}$ or so before lunch with little trouble. On starting off after lunch, during which she had felt sleepy, nauseated and anorexic, she became rapidly dyspnoeic in exertion, weak, dizzy and drowsy to such an extent that she would go off to sleep if left resting for more than five minutes.
Physical examination revealed an exhausted pale but not cyanosed individual, her chest clear to auscultation, and dextrostix excluded hypoglycaemia. She was also noted to be staggering occasionally. A diagnosis of altitude sickness was made and descent $\stackrel{.}{\Rightarrow}$ started.

Within $500 \mathrm{ft}$ of descent there was an improvement $\overline{0}$ in her condition and by the time the starting altitude of $\frac{}{\sigma}$ $8,500 \mathrm{ft}$ was reached, she felt normal again, but had $\frac{\bar{\rho}}{\frac{\sigma}{\sigma}}$ partial amnesia for events further up. The remaining $\mathbb{Q}$ member of the party crossed the pass and completed the trek with minimal problems due to altitude.

Acute mountain sickness has been reported at $\vec{\circ}$ altitudes as low as 7,000 ft (Beeson \& McDermott, $\vec{\omega}$ 1979) and acetazolamide is known to be a useful $\stackrel{\sigma}{\sigma}$ prophylactic (Green et al., 1981; Larson et al., 1979) $\overparen{B}$ for the condition. However, it is not a panacea 3 . (Editorial, 1981), and this is emphasized by this girl, $\stackrel{9}{-}$ who despite taking acetazolamide developed marked altitude sickness at an altitude frequently reached both $\vec{G}$ in Europe and the Himalayas. Immediate descent produced a rapid and sustained improvement in her $\overrightarrow{1}$ physical condition.

$$
\begin{array}{r}
\text { I. Wilson } \\
\text { Princess Mary's RAF Hospital Halton } \\
\text { Aylesbury } \\
\text { Bucks HP225P }
\end{array}
$$

\section{References}

BEESON, P.B. \& MCDERMOTT, W. (eds) (1979). Textbook Medicine 15th edition, p. 101. W.B. Saunders: Philadelphia.

EDITORIAL (1981). British Medical Journal, 283, 396.

GREENE, M.K., KERR, A.M., McINTOSH, I.B. \& PRESCOTT, R.J. (1981). Acetazolamide in prevention of acute mountain sickness: a double blind crossover study. British Medical Journal, 283, 811.

LARSON, E.B., ROACH, R.C., SCHOENE, R.B. \& HORNBEIN, T.F. (1982). Acute mountain sickness and acetazolamide: clinical efficacy and effect on ventilation. Journal of the American Medical Association, 248, 328. 